\title{
An Unusual Cause of Hypoglycemia: Insulin Autoimmune Syndrome
}

\author{
Yasemin AYDOGAN UNSAL ${ }^{1}$ (D) , Ozen OZ GUL ${ }^{1}$ (D) , Soner CANDER $^{1}$ (D) , Canan ERSOY $^{1}$ (D) , \\ Oktay UNSAL ${ }^{2}$ (i) , Ensar AYDEMIR ${ }^{1}$ (D) Erdinc ERTURK $^{1}$
}

${ }^{1}$ Division of Endocrinology and Metabolism, Department of Internal Medicine, Bursa Uludag University Faculty of Medicine, Bursa, Turkey

${ }^{2}$ Division of Medical Oncology, Department of Internal Medicine, Gazi University Hospital Department of Medical Oncology, Ankara, Turkey

\begin{abstract}
Insulin autoimmune syndrome (IAS) is a rare cause of hyperinsulinemic hypoglycemia characterized by antibodies to endogenous insulin without exposure to exogenous insulin. In this report, we presented a case of insulin autoimmune syndrome with a history of fasting hypoglycemia. After work up and exclusion of other causes such as insulinoma, hyperinsulinemic hypoglycemic state of the patient was considered to have been induced by etofenamate. Although IAS is generally self-limiting and dietary management and withdrawal of trigger drug are enough to maintain euglycemia, in some cases corticosteroids, plasmapheresis, rituximab can be used for treatment. In our case, despite dietary management, hypoglycemia was severe and the patient's life quality was adversely affected. After treatment with prednisolone, hypoglycemic episodes became less and less frequent. IAS should be considered as a differential diagnosis of hyperinsulinemic hypoglycemic states to avoid unnecessary interventions.
\end{abstract}

Turk J Int Med 2021;3(1):32-36

DOI: $\underline{10.46310 / \text { tjim.786828 }}$

Keywords: insulin autoimmune syndrome, hyperinsulinemic hypoglycemic state, corticosteroids

\section{Introduction}

Insulin autoimmune syndrome (IAS) is characterized by hypoglycemia and presence of antibodies to endogenous insulin in insulin naive patients. This syndrome is also known as Hirata's disease who first described the syndrome in $1970 .{ }^{1}$
Viruses and mostly drugs trigger formation of antiinsulin antibodies. Autoantibodies bind to insulin molecules secreted from pancreas following meal and rendering them unable to exert their effects. As glucose concentration falls, insulin molecules dissociate from the autoantibodies and causes hypoglycemia. $^{2}$ 
In IAS, insulin and C-peptide levels are high and antibodies to insulin are positive. The patients are not having a history of exposure to exogenous insulin. Several autoimmune diseases can be associated with this syndrome. The first line treatment is withdrawal of trigger drug and diet with low glycemic index but in some severe cases other treatment strategies can be considered like prednisolone.

\section{Case Report}

A 55-year-old male patient with a history of hypertension and chronic obstructive pulmonary disease was presented to endocrinology clinic with a month history of symptoms of hypoglycemia such as weakness and sweating. Hypoglycemia attacks were occurred in the fasting period and alleviated with food intake. Detailed history review did not identify any suspicion for insulin and/or insulin secretagogues, herbal substances. He did not smoke or drink alcohol. There was no known diagnosis of diabetes mellitus in the patient and his family history. His symptoms of hypoglycemia had started after using etofenamate, nonsteroidal anti-inflammatory medication, administered intramuscularly due to lower back pain for a month. Vital signs were normal and physical examination was not significant.

In laboratory evaluation, complete blood count, renal, liver and thyroid function tests were normal. ACTH - cortisol axis was evaluated as normal. A random blood glucose level was 146 $\mathrm{mg} / \mathrm{dL}$. During the follow up, fingerstick blood glucose levels were observed as in Table 1.
When the patient's fingerstick blood glucose level was $44 \mathrm{mg} / \mathrm{dL}$, he was symptomatic and experienced sweating and weakness. Blood samples were collected during hypoglycemic attack and then he was given continuous intravenous infusion of dextrose to sustain euglycemia. Laboratory investigations taken during hypoglycemia indicated that hypoglycemia was associated with markedly increased insulin and C-peptide levels compatible with hyperinsulinemic hypoglycemic state (Table 2).

There was no pathological finding in the abdominal computed tomography evaluated for insulinoma. Selective arterial calcium stimulation test was performed to differentiate pancreatic pathologies.

Regardless of the sampling site, all specimens taken from different site had raised insulin and C-peptide levels (Table 3). As insulin to C-peptide molar ratio $>1$ and autoantibodies to insulin were found to be markedly increased at more than $100 \mathrm{IU} / \mathrm{mL}$ (reference range: 0-10 IU/mL), autoimmune hypoglycemia was considered as the cause of hypoglycemia.

Etiology of autoimmune hypoglycemia was considered due to usage of etofenamate; so that it was discontinued. The patient was advised to start a low glycemic index diet with frequent small meals. The diet was insufficient to improve the hypoglycemic attacks so that prednisolone treatment was started as $30 \mathrm{mg}$ daily. Work up for other autoimmune diseases revealed increased anti-double stranded DNA (anti-dsDNA) level of $38 \mathrm{IU} / \mathrm{mL}$ (12-18) and positive anti-nuclear antibody (ANA) level, elevated anti thyroid

Table 1. Fingerstick blood glucose levels

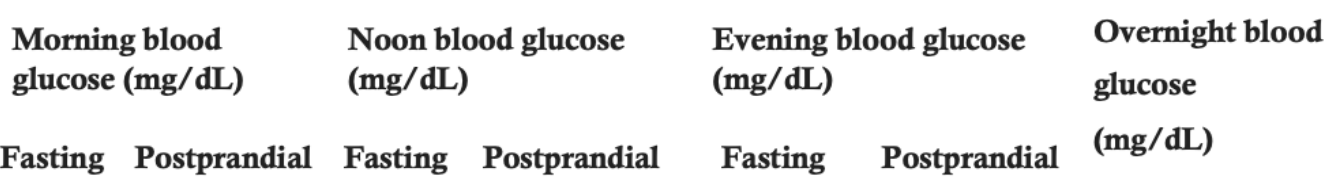

First day

Second day 56

87

59

Third day

41

78

205

214

166

103

$69-157$ 
Table 2. Laboratory investigations performed during hypoglycemic period

\section{Parameters}

Serum glucose $(\mathrm{mg} / \mathrm{dL})$

Serum insulin (mIU/L)

Serum C-peptide $(\mu \mathrm{g} / \mathrm{L})$

Insulin/C-peptide molar ratio
Results

44

$>600$

7

$>85.7$

\section{Reference ranges}

$70-100$

$2.6-24.9$

$0.78-5.19$

$<1$ peroxidase antibody (anti-TPO) level of $34.8 \mathrm{KU} / \mathrm{L}(0-5.61)$, elevated anti thyroglobulin antibody level of $20 \mathrm{KU} / \mathrm{L}$ (0-4.11). Imaging studies for thyroid gland was compatible with autoimmune thyroid disease. After consultation to rheumatology clinic, no pathology was considered. Also, blood work for monoclonal gammopathy was not significant.

During hospital stay, the occurrence of hypoglycemic episodes decreased, and he was stopped intravenous dextrose infusion. Since he remained euglycemic with treatment of prednisolone, dosage of treatment was gradually decreased to $20 \mathrm{mg} /$ day.

At his follow up visit, two months after discharge from hospital, hypoglycemia did not occur and his dosage of prednisolone treatment was decreased to $15 \mathrm{mg} /$ day. His most recent laboratory investigations demonstrated persistently raised anti insulin antibody levels $>100 \mathrm{IU} / \mathrm{mL}$ (reference range: $0-10 \mathrm{IU} / \mathrm{mL}$ ). In the follow up of the patient, it was planned that the prednisolone treatment should be gradually decreased and discontinued.

\section{Discussion}

IAS is a rare cause of hyperinsulinemic hypoglycemia. This syndrome is characterized by autoantibodies to endogenous insulin without pathology of pancreatic islet cells in patients without history of previous exposure to exogenous insulin. ${ }^{3}$ It is usually seen in adults older than 40 years of age. At least 400 cases have been seen in $\mathrm{Japan}^{4}$ and it is more common in Asian people.

The etiology of antibody formation is multifactorial. Exposure to drugs, viral infections like mumps, rubella, influenza, measles, autoimmune diseases like Graves' disease, hematologic diseases like multiple myeloma can trigger autoimmune hypoglycemia syndrome..$^{5-7}$ Also, strong association was observed with the presence of human leukocyte antigen (HLADR4) in cases. ${ }^{8}$ IAS is associated with exposure to medications containing a sulfhydryl group like methimazole, captopril, hydralazine, procainamide etc. ${ }^{9}$ In the literature, patients developed IAS response to nonsteroidal antiinflammatory drugs such as loxoprofen

Table 3. Selective arterial calcium stimulation test results

Time (seconds)

\begin{tabular}{rccc} 
& $\begin{array}{c}\text { Superior mesenteric } \\
\text { artery }\end{array}$ & $\begin{array}{c}\text { Gastroduodenal } \\
\text { artery }\end{array}$ & $\begin{array}{c}\text { Splenic } \\
\text { artery }\end{array}$ \\
\hline 0. sec & & & \\
$\mathbf{2 0 .} \mathbf{s e c}$ & 2082.6 & 2028.9 & 2088.6 \\
$\mathbf{4 0 .} \mathbf{s e c}$ & 2026.3 & 2162.8 & 2121.5 \\
$\mathbf{6 0 .} \mathbf{s e c}$ & 2021.4 & 2116.8 & 2064.6 \\
& 2098.6 & 2117.5 & 2109.4
\end{tabular}


sodium and diclofenac sodium. In our case unlike the literature, onset of hypoglycemia after intake of etofenamate treatment of lower back pain suggested IAS. ${ }^{3}$

After food intake, autoantibodies bind to secreted insulin and proinsulin making the insulin to be ineffective. This causes postprandial hyperglycemia and increasing insulin release from pancreas. After dissociation insulin from antibodies, high levels of insulin cause hypoglycemia. ${ }^{5}$

Hypoglycemia can be observed on fasting state or postprandially in IAS. In our case fasting hypoglycemia was observed. The patient experienced hypoglycemia symptoms especially in the overnight period and before breakfast in the morning. Due to insulinoma is the first preliminary diagnosis that comes to mind, with the combination of fasting hypoglycemia and endogenous hyperinsulinemia, the investigations planned in this direction. Because of no mass in pancreas in the abdominal computed tomography, very high levels of insulin and C-peptide, excessively high values at insulin levels in all samples in the calcium stimulation test and positivity of anti-insulin antibody, autoimmune hypoglycemia was considered as diagnosis in our case. Positivity of ANA and elevated thyroid autoantibodies supported the association of IAS and autoimmunity.

In IAS, antibody bounds to insulin, half-life of insulin increases from 5 minutes to hours, while the half-life of C-peptide usually remains unaffected (30-35 minutes). ${ }^{10}$ Patient with IAS thus have more than one insulin to C-peptide molar ratio.

IAS is generally self-limiting, and most patients can achieve remission of the disease after stopping use of the medication. ${ }^{11}$ Food with low glycemic index remains the first line of the treatment to avoid postprandial hyperglycemia and then secretion of insulin. In more severe cases like in our case, euglycemia can be achieved by using corticosteroid therapy.

As we did not consider interference from heterophile antibodies, we did not do heterophile antibody test. Treatment with prednisolone and then clinical improvement of the patient may suggest that interference was low.

Consequently, for diagnosis, patient's detailed history including age, sex, personel and family history of diseases such as autoimmune and hematological diseases, intake of any drugs or health supplements, infections, time and mode of hypoglycemia is very important. In all hyperinsulinemic hypoglycemic cases, especially in patients taking medications known to be associated with this syndrome and having very high insulin levels, the diagnosis of IAS should be kept in mind.

\section{Conclusion}

IAS should be considered as a differential diagnosis in hyperinsulinemic hypoglycemic patient to avoid any unnecessary and invasive procedures.

\section{Conflict of Interests}

Authors declare that there are none.

\section{References}

1. Hirata $\mathrm{Y}$, Ishizu $\mathrm{H}$, Ouchi $\mathrm{N}$, Motomura $\mathrm{S}$, Abe $\mathrm{M}$, Hara Y, Wakasugi H, Takahashi I, Sakano H, Tanaka M, Kawano H, Kanesaki T. Insulin autoimmunity in a case of spontaneous hypoglycemia. J Jpn Diabetes Soc. 1970;13:312-20.

2. Redmon JB, Nuttall FQ. Autoimmune hypoglycemia. Endocrinol Metab Clin North Am. 1999 Sep;28(3):60318, vii. doi: 10.1016/s0889-8529(05)70090-6.

3. Uchigata Y, Hirata Y. Insulin autoimmune syndrome (IAS, Hirata disease). Ann Med Interne (Paris). 1999 Apr;150(3):245-53.

4. Han JS, Moon HJ, Kim JS, Kim HI, Kim CH, Kim MJ. Anti-tuberculosis treatment-induced insulin autoimmune syndrome. Ewha Med J. 2016 Oct 31;39(4):122-4. doi: 10.12771/emj.2016.39.4.122.

5. Ismail AA. The insulin autoimmune syndrome (IAS) as a cause of hypoglycaemia: an update on the pathophysiology, biochemical investigations and diagnosis. Clin Chem Lab Med. 2016 Nov 1;54(11):1715-24. doi: 10.1515/cclm-20151255.

6. Lupsa BC, Chong AY, Cochran EK, Soos MA, Semple RK, Gorden P. Autoimmune forms of hypoglycemia. Medicine (Baltimore). 2009 May;88(3):141-53. doi: 10.1097/MD.0b013e3181a5b42e.

7. Takei M. Insulin auto-antibodies produced by methimazole treatment in the patients with Graves' disease. J Tokyo Women Med Coll. 1980;50:54-68.

8. Uchigata Y, Omori Y, Nieda M, Kuwata S, Tokunaga $\mathrm{K}$, Juji T. HLA-DR4 genotype and insulin-processing in insulin autoimmune syndrome. Lancet. 1992 Dec 12;340(8833):1467. doi: 10.1016/0140-6736(92)92654-x.

9. Yamada T, Imai J, Ishigaki Y, Hinokio Y, Oka Y, Katagiri $\mathrm{H}$. Possible relevance of HLA-DRB1*0403 haplotype in insulin autoimmune syndrome induced by alpha-lipoic 
acid, used as a dietary supplement. Diabetes Care. 2007 Dec;30(12):e131. doi: 10.2337/dc07-1636.

10. Ismail AA. The double whammy of endogenous insulin antibodies in non-diabetic subjects. Clin Chem Lab Med.
2008;46(2):153-6. doi: 10.1515/CCLM.2008.031.

11. Uchigata Y, Hirata Y, Iwamoto Y. Drug-induced insulin autoimmune syndrome. Diabetes Res Clin Pract. 2009 Jan;83(1):e19-20. doi: 10.1016/j.diabres.2008.10.015. 